\title{
Medical professionalism: Development and validation of the Arabian LAMPS
}

Citation for published version (APA):

Al-Eraky, M. M., Chandratilake, M., Wajid, G., Donkers, J., \& van Merrienboer, J. (2013). Medical professionalism: Development and validation of the Arabian LAMPS. Medical Teacher, 35, S56-S62. https://doi.org/10.3109/0142159X.2013.765553

Document status and date:

Published: 01/01/2013

DOI:

10.3109/0142159X.2013.765553

Document Version:

Publisher's PDF, also known as Version of record

Document license:

Taverne

Please check the document version of this publication:

- A submitted manuscript is the version of the article upon submission and before peer-review. There can be important differences between the submitted version and the official published version of record.

People interested in the research are advised to contact the author for the final version of the publication, or visit the DOI to the publisher's website.

- The final author version and the galley proof are versions of the publication after peer review.

- The final published version features the final layout of the paper including the volume, issue and page numbers.

Link to publication

\footnotetext{
General rights rights.

- You may freely distribute the URL identifying the publication in the public portal. please follow below link for the End User Agreement:

www.umlib.nl/taverne-license

Take down policy

If you believe that this document breaches copyright please contact us at:

repository@maastrichtuniversity.nl

providing details and we will investigate your claim.
}

Copyright and moral rights for the publications made accessible in the public portal are retained by the authors and/or other copyright owners and it is a condition of accessing publications that users recognise and abide by the legal requirements associated with these

- Users may download and print one copy of any publication from the public portal for the purpose of private study or research.

- You may not further distribute the material or use it for any profit-making activity or commercial gain

If the publication is distributed under the terms of Article $25 \mathrm{fa}$ of the Dutch Copyright Act, indicated by the "Taverne" license above, 


\title{
Medical Teacher
}

\section{Medical professionalism: Development and validation of the Arabian LAMPS}

\author{
Mohamed M. Al-Eraky, Madawa Chandratilake, Gohar Wajid, Jeroen Donkers \\ \& Jeroen van Merriënboer
}

To cite this article: Mohamed M. Al-Eraky, Madawa Chandratilake, Gohar Wajid, Jeroen Donkers \& Jeroen van Merriënboer (2013) Medical professionalism: Development and validation of the Arabian LAMPS, Medical Teacher, 35:sup1, S56-S62, DOI: 10.3109/0142159X.2013.765553

To link to this article: https://doi.org/10.3109/0142159X.2013.765553

曲 Published online: 12 Apr 2013.

Submit your article to this journal $\sqsubset$

Llll Article views: 560

Q View related articles ¿

4 Citing articles: 2 View citing articles 준 


\title{
Medical professionalism: Development and validation of the Arabian LAMPS
}

\author{
MOHAMED M. AL-ERAKY ${ }^{1,2}$, MADAWA CHANDRATILAKE ${ }^{3}$, GOHAR WAJID ${ }^{1}$, JEROEN DONKERS ${ }^{4}$ \& \\ JEROEN VAN MERRIËNBOER ${ }^{4}$ \\ ${ }^{1}$ University of Dammam, Saudi Arabia, ${ }^{2}$ Zagazig University, Egypt, ${ }^{3}$ University of Dundee, UK, ${ }^{4}$ Maastricht University, \\ The Netherlands
}

\begin{abstract}
Aim: This study aims to develop and validate a questionnaire that measures attitudes of medical students on professionalism in the Arabian context.

Method: Thirty-two experts contributed to item generation in particular domains. The instrument was administered to Arab medical students and interns and responses were collected using five-point Likert scale. Data were analyzed to estimate the reliability of the instrument. The inventory in its final version was labeled as the Learners' Attitude of Medical Professionalism Scale (LAMPS)
\end{abstract}

Results: A total of 413 medical students and interns responded from two universities in Egypt and Saudi Arabia. Means of item response ranged from 2.38 to 4.72 . The highest mainly deals with "Respect to others," while the lowest belong to "Honor/Integrity." The final version of the LAMPS has 28 items in five domains, with a reliability of 0.79 .

Discussion: The LAMPS has salient features compared to other similar instrument. It was designed based on a reliable framework in explicit behavioral items, not abstract attributes of professionalism. The LAMPS can help teachers to identify learning gaps regarding professionalism amongst their students and track attitude changes over time or as the result of interventions.

Conclusion: To the best of our knowledge, the LAMPS is the first context-specific inventory on medical professionalism attitudes in the Arabian context.

\section{Introduction}

Medical professionalism rests on "a contractual relationship with a series of obligations and expectations based on mutual trust between the society and medicine" (Cruess 2006). Professionalism is a culture-sensitive construct and, therefore, is perceived and expressed with respect to local customs, beliefs, and cultures (Cruess et al. 2010; Chandratilake et al. 2012). This has initiated a global trend of re-visiting professionalism education and, as a result, professionalism has become an explicit component of medical curricula (ABIM 1995; ACGME 2011; Zaini et al. 2011). Cruess (2006) argues that professionalism must be taught through the formal curriculum in the form of planned teaching and learning sessions and be assessed throughout the continuum of medical education. Although professionalism education is gaining momentum in the Arabian context, the literature from that region on that topic is still scarce. Arabian teachers and students feel that professionalism education remains as a gap in formal curricula (Sadat-Ali 2004) and they consider professionalism as a major contributor to the bidden curriculum, rather than the formal one (Adkoli et al. 2011).

Incorporating professionalism in medical education should be based on the core attributes of what people think of a professional doctor in a particular culture. A number of studies reported the attitudes on professionalism among students

\section{Practice points}

- Professionalism is culture-sensitive and the situations used to measure its constructs or domains should reflect the cultural differences.

- Teaching professionalism should rely on needs assessment with respect to the context of the learners

- The Learners' Attitudes on Medical Professionalism Scale (LAMPS) is the first context-specific, reliable, and valid inventory on medical professionalism in the Arabian context.

- The LAMPS can help teachers to identify learning gaps regarding professionalism amongst their students.

- The LAMPS can be used to track attitude changes regarding professionalism over time or as the result of interventions.

(Szauter \& Turner 2001; Tsai et al. 2007), residents (Chard et al. 2006; Ephgrave et al. 2006), faculty members (Quaintance et al. 2008; Hur 2009), patients (Davis et al.2007; Wiggins et al. 2009), and the public at large (Chandratilake et al. 2010).

The attitude of medical students toward professionalism is of great educational value, because they are supposed to be the future professionals. The "socially-exclusive" medical students, as described by Blakey et al. (2008), enter medical 
school with positive attitudes toward professionalism attributes. Their personal standards and ethics are driven from past exposure to family, teachers, friends, and other social contacts (Nath et al. 2006). Exploring students' attitudes has been used widely to measure different components of professionalism and related areas in the Western context (Chard et al. 2006; Blackall et al. 2007; Finn et al. 2010), SouthAsian context (Tsai et al. 2007; Hur 2009), and Turkish context (Sehiralti et al. 2010), but unfortunately, none has been validated and contextualized to be used in the Arabian context. By Arabian context, we mean the culture, traditions, beliefs, and behaviors that are being practiced by nations of Arabian countries in the Middle-East, where Arabic is the official language and Islam is the religion of the majority of the population. Those behaviors and traditions are not necessarily driven from Islamic doctrines, but some common values have been accepted as the norm among populations of these countries (Barakat 1993).

The American Board of Internal Medicine (ABIM) identified six domains as a framework of medical professionalism (ABIM 1995). In a previous study, we have used these domains as a basis to define a framework for medical professionalism in a consensus survey recruiting professionals who validated the ABIM domains in the Arabian context (Al-Eraky \& Chandratilake 2012). They accepted all six domains of the ABIM framework, yet a new seventh domain, namely "Professional Autonomy," emerged.

Medical students, however, do not know how attributes of professionalism function in practice (Blue et al. 2009). Therefore, to measure their attitudes on professionalism, a questionnaire should be developed in expressive behaviors (Green et al. 2009) to operationalize these seven domains into behavioral items. The aim of this study is two-fold. First, it aims to develop a questionnaire based on the seven domains to measure the attitude of Arabian medical students toward medical professionalism. Second, it aims to validate this questionnaire.

\section{Methodology}

The instrument that will be developed is called the Learners' Attitudes on Medical Professionalism Scale (LAMPS). Development of the LAMPS passes through four steps: (1) defining the constructs/domains of professionalism that are being measured, (2) generating behavioral items to represent each domain, (3) pilot testing of the LAMPS, and (4) finalizing the scale based on data collected in Step 3.

\section{Step 1: Defining the construct}

Thirty-two experts volunteered to contribute to content validation of domains and item generation. The panelists were a convenient but representative sample of different disciplines and seniority levels from both genders. Panelists were provided with definitions of the seven domains of professionalism to be clear on the constructs being measured.

\section{Step 2: Item generation}

As a rationale step, authors developed 35 behavioral items to represent the seven domains of professionalism. We invited the panelists to review these items and sort out each item in one single construct/domain, based on the definitions provided earlier. Item categorization into domains was done by counting the votes, which were received independently from each member of the reference panel. When votes for a particular item were dispersed over more than one domain, the item was considered multi-directional (query) and, therefore, excluded from the initial pool before pilot testing.

We further asked the panelists to suggest new situations (behavioral items), if any, from their current practice and indicate their domain. They submitted 17 more items to the authors independently without communicating with their peers. Subsequently, it was expected to find closely related scenarios or even addressing almost the same situation. These items were considered redundant, but we decided to keep them in pilot testing and postpone "trimming" of the instrument after checking the internal consistency of subscales for different domains.

\section{Step 3: Pilot testing}

Participants. We targeted medical students and interns from Zagazig University in Egypt and Dammam University in Saudi Arabia, who filled the questionnaire.

Data collection. The inventory was translated to Arabic to minimize the misinterpretation of items and reviewed by two independent native Arabic speakers. The preliminary version of the instrument was distributed in a paper format by hand to medical students and interns. Seven teachers volunteered to distribute the survey questionnaire to students in both the universities. A cover letter was attached to standardize instructions to all participants. The cover letter explained the objectives of the study and instructed students to indicate what they personally thought of the behavior in each situation, not what they saw as "common" in practice.

Data analysis. Five-point Likert scale was used to record responses on items. For positively-worded item statements that represented professional behaviors, we used a scale of 1 to 5 ( $1=$ strongly disagree, $5=$ strongly agree). For negativelyworded statements that represent unprofessional behaviors, the scale was reversed ( $1=$ strongly agree, $5=$ strongly disagree). Mean and standard deviation for each item and domain were reported, along with the reliability using Cronbach's alpha.

\section{Step 4: Finalizing the LAMPS}

The final version of the LAMPS was contoured in light of different aspects of validity and reliability of domains and items of each domain. In content validation, we found some commonalities of behaviors between specific pairs of domains, while other domains remain. In the original validated framework of the ABIM, Honor/Integrity was the title of a single domain. Likewise, we decided to merge two pairs of domains 


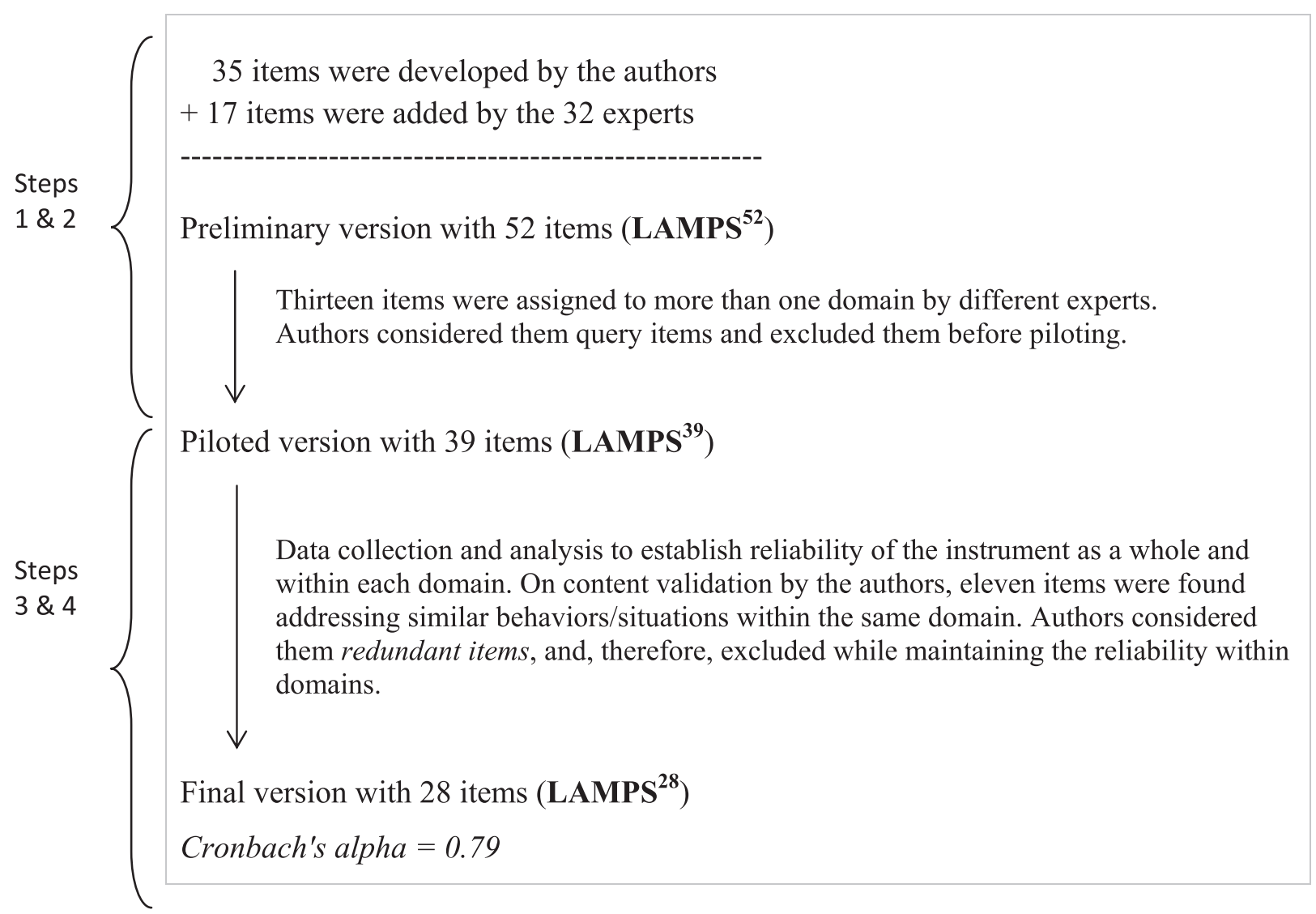

Figure 1. Evolution of the LAMPS through its four developmental stages.

together; Duty/Accountability and Excellence/Autonomy. Items of the LAMPS, therefore, were sorted out into five final domains, rather than seven. We found it more practical for identifying learning gaps and designing modules on particular areas in professionalism.

In item filtration, our objective was not to maximize the reliability at the expense of validity, i.e. we did not exclude important items that address common behaviors just to get higher alpha coefficient. It was rather a tradeoff between maximizing, validating, and achieving an appropriate number of items that address important aspects of each domain. Throughout the four steps in development and validation, the LAMPS has been matured through a number of processes, while excluding query and redundant items, till it has been evaluated in its final shape (Figure 1).

\section{Results}

\section{Descriptive statistics}

A total of 413 responses were received from Egyptians and Saudi medical students and interns from two universities. The mean scores of items varies between 2.38 ( $S D=1.20$, scale $1-$ 5) and $4.72(\mathrm{SD}=0.67$, scale $1-5)$. The highest scoring items mainly deal with the domain of "Respect to others," while the lowest ones mostly belong to "Honor/Integrity." The final version of the LAMPS has 28 items and is presented in Table 1.

\section{Reliability of the LAMPS}

Cronbach's alpha of 0.70 or more normally indicates acceptable internal consistency (Gable \& Wolf 1993). The reliability of the final version of the LAMPS was 0.79 , which can be considered high in view of the multifaceted nature of the construct being measured (medical professionalism). Pett and colleagues (2003) argued that inter-item correlation for items intended to measure the same factor/domain should be moderate, but not too high (i.e. between 0.30 and 0.60), because higher inter-item correlations within the domain suggest that each separate item does not contribute something unique to the construct. The internal consistency of the subscales/domains of the LAMPS ranged from 0.42 to 0.57 (Table 2).

\section{Discussion}

The LAMPS is intended to measure attitudes of Arabian medical students and interns toward medical professionalism. We claim that the LAMPS is fit for its purpose, because it stems from the ABIM framework of professionalism. The ABIM domains have been used repeatedly as a basis to develop similar instruments, not only in the USA as its original context (Robins et al. 2002; Roberts et al. 2004; Ratanawongsa et al. 2006; Blackall et al. 2007; Quaintance et al. 2008), but also in non-Western cultures such as Taiwan (Tsai et al. 2007), Iran (Aramesh et al. 2009), and Japan (Suzuki 2009). 
Behavioral item within domains "Do you agree when the doctor...?"

Duty/Accountability

1. Admits wrong diagnosis before a patient

2. Leaves before handing over patients to the next colleague on duty

3. Actively participates in orientation for new residents

4. Encourages patients to contribute to decision making

5. Discusses patients cases with colleagues in a crowded elevator

6. Calls insurance company to follow up a valid patient claim

7. Declines an invitation to an infection control committee meeting

\section{Excellence/Autonomy}

1. Reflects on clinical cases to discover his/her unmet learning needs

2. Attends patient's questions to explain their illness in a busy clinic

3. Searches for the best evidence available in patient care

4. Collaborates with colleagues to draft new hospital guidelines

5. Invests part of his/her income on attending medical conferences

6. Makes a deal with a pharma company to sponsor his/her conference

\section{Honor/Integrity}

1. Gives wrong information to a patient to protect a colleague

2. Issues a false sick leave for a kid of a friend to study home

3. Changes actual data in his/her research based on supervisor's advice

4. Hides information about fatal diagnosis to avoid patient disturbance

5. Introduces medical students as doctors to patients

Altruism

1. Declines sport club to respond to an emergency call

2. Frequently skips clinical teaching to prepare for a conference

3. Cancels a family appointment for an urgent patient's need

4. Does not witness against employer hospital in favor of a patient before the court

5. Turns down a home visit to a disable patient due to busy clinic

Respect

1. Respects the roles of all members of the healthcare team in the department

2. Considers patient background when explaining their clinical illness

3. Keeps patients waiting in his/her clinic without apology

4. Gives priority to some patients based on social status or nationality

5. Criticizes a prescription written by a colleague in front of patients

\begin{tabular}{|c|c|c|c|}
\hline Authorship & Wording & Mean & SD \\
\hline Pn. & + ve & 4.35 & 0.78 \\
\hline Pn. & $-v e$ & 4.25 & 0.79 \\
\hline Pn. & + ve & 4.16 & 0.72 \\
\hline $\mathrm{Au}$. & $+v e$ & 4.16 & 0.81 \\
\hline $\mathrm{Au}$. & $-v e$ & 4.10 & 0.95 \\
\hline Pn. & $+\mathrm{ve}$ & 3.77 & 0.91 \\
\hline Pn. & $-v e$ & 3.30 & 0.91 \\
\hline $\mathrm{Au}$. & $+\mathrm{ve}$ & 4.61 & 0.67 \\
\hline Pn. & $+v e$ & 4.37 & 0.74 \\
\hline $\mathrm{Au}$. & + ve & 4.37 & 0.79 \\
\hline $\mathrm{Au}$. & $+v e$ & 4.30 & 0.74 \\
\hline $\mathrm{Pn}$. & + ve & 3.51 & 0.95 \\
\hline $\mathrm{Au}$. & $-v e$ & 3.38 & 1.11 \\
\hline $\mathrm{Au}$. & $-v e$ & 4.37 & 0.85 \\
\hline $\mathrm{Au}$. & $-v e$ & 3.98 & 1.04 \\
\hline $\mathrm{Au}$. & $-v e$ & 3.47 & 1.01 \\
\hline $\mathrm{Au}$. & $-v e$ & 3.34 & 1.17 \\
\hline $\mathrm{Au}$. & $-v e$ & 2.38 & 1.20 \\
\hline $\mathrm{Au}$. & + ve & 4.45 & 0.77 \\
\hline $\mathrm{Au}$. & $-v e$ & 4.24 & 0.92 \\
\hline $\mathrm{Au}$. & + ve & 4.15 & 0.82 \\
\hline Pn. & $-v e$ & 3.78 & 0.99 \\
\hline $\mathrm{Pn}$. & $-v e$ & 3.44 & 0.93 \\
\hline $\mathrm{Au}$. & $+v e$ & 4.72 & 0.67 \\
\hline $\mathrm{Au}$. & + ve & 4.66 & 0.62 \\
\hline $\mathrm{Au}$. & $-v e$ & 4.54 & 0.75 \\
\hline $\mathrm{Au}$. & $-v e$ & 4.47 & 0.89 \\
\hline Pn. & $-v e$ & 4.29 & 0.82 \\
\hline
\end{tabular}

Notes: Authorship: Au.: proposed by the authors, Pn.: added by the panel of expert. Wording: +ve: Positively-worded item, -ve: Negatively-worded item.

Items are sorted out within each domain in a descending order, based on their means.
Table 2. Means and reliability of domains of the LAMPS.

\begin{tabular}{|lccc|}
\hline Domain & $\begin{array}{c}\text { Number } \\
\text { of items }\end{array}$ & Mean & $\begin{array}{c}\text { Reliability by } \\
\text { Cronbach's alpha* }\end{array}$ \\
Respect & 5 & 4.53 & 0.57 \\
Excellence/Autonomy & 6 & 4.09 & 0.48 \\
Altruism & 5 & 4.02 & 0.42 \\
Duty/Accountability & 7 & 4.01 & 0.57 \\
Honor/Integrity & 5 & 3.50 & 0.43 \\
\hline
\end{tabular}

Note: *Reliability within each factor/domain should be moderate ranging from 0.3 to 0.6 (Pett 2003).

Moreover, the same domains were found to be appropriate for the Arabian context in a previous study (Al-Eraky \& Chandratilake 2012).

\section{Evidence for validity}

Content-related evidence of validity refers to the content and format of the LAMPS. How comprehensive is the content?
How adequately does the sample of items represent the domains of professionalism? Using an existing reference framework, like the ABIM domain, is a highly recommended method in establishing the content validity of a measurement (Clark \& Watson 1995). Jha (2006) reported that most studies define professionalism in vague terms like altruism, humanism, and excellence, while few studies "operationalized" medical professionalism in behaviors. Green (2009), however, argued that tangible behaviors, not domains, are important to facilitate discussion, assessment, and modeling of professionalism. Unlike other similar instruments, the LAMPS is designed in expressive behavioral items in the form of micro-vignettes, which are developed and reviewed by the authors along with 32 panelists. The wording of these vignettes was reviewed by two independent Arabic native professionals, who did not contribute to authoring the items to safeguard the clarity of each vignette.

In pilot testing the LAMPS, students were instructed to report their own perceptions on different micro-vignettes on professionalism, not what they experienced from doctors around them in the local environment. This helped students to focus on the construct that was being measured. 


\section{Table 3. A comparison between the LAMPS and three similar instruments on professionalism.}

\begin{tabular}{|c|c|c|c|c|}
\hline Instrument & Nath (2006) & Tsai (2007) & Blackall (2007) & The LAMPS \\
\hline Objective of the study & $\begin{array}{l}\text { To assess whether the per- } \\
\text { ception of what consti- } \\
\text { tuted professionalism } \\
\text { varies with age, disci- } \\
\text { pline, gender, and edu- } \\
\text { cational level. }\end{array}$ & $\begin{array}{l}\text { To explore how Taiwanese } \\
7 \text { th year medical stu- } \\
\text { dents value medical } \\
\text { professionalism. }\end{array}$ & $\begin{array}{l}\text { To examine attitudes } \\
\text { toward professionalism. }\end{array}$ & $\begin{array}{l}\text { To develop and validate an } \\
\text { inventory to measure } \\
\text { attitudes of medical stu- } \\
\text { dents toward medical } \\
\text { professionalism in the } \\
\text { Arabian context. }\end{array}$ \\
\hline Target groups & $\begin{array}{l}\text { Medical students, residents, } \\
\text { and faculty members. }\end{array}$ & Senior medical students. & $\begin{array}{l}\text { Medical students, residents, } \\
\text { and faculty members. }\end{array}$ & $\begin{array}{l}\text { Medical students and } \\
\text { interns. }\end{array}$ \\
\hline Country & USA & Taiwan & USA & Egypt \& Saudi Arabia \\
\hline Domains & Not identified & $\mathrm{ABIM}$ & ABIM & ABIM \\
\hline Items ${ }^{\star}$ & 29 items & 32 items & 36 items & 28 items \\
\hline Items were developed & By the panel & By medical experts & By the panel & $\begin{array}{l}\text { Jointly by the authors and } \\
\text { the panel }\end{array}$ \\
\hline Reference panel & 7 members & Not identified & 9 members & 32 members \\
\hline Leading question & $\begin{array}{l}\text { How do you classify the } \\
\text { following behavior? }\end{array}$ & $\begin{array}{l}\text { How do you rate the } \\
\text { importance of the fol- } \\
\text { lowing attribute of } \\
\text { professionalism? }\end{array}$ & $\begin{array}{l}\text { To what extent the item } \\
\text { reflects your definition of } \\
\text { professionalism? }\end{array}$ & $\begin{array}{l}\text { Do you agree when the } \\
\text { doctor...? }\end{array}$ \\
\hline Scale & $\begin{array}{l}\text { Three option: } \\
\text { - Professional } \\
\text { - Unprofessional } \\
\text { - Unrelated to } \\
\text { professionalism }\end{array}$ & $\begin{array}{l}\text { Five-point Likert scale } \\
\text { - Extremely important } \\
\text { - Important } \\
\text { - Uncertain } \\
\text { - Not important } \\
\text { - Least important }\end{array}$ & $\begin{array}{l}\text { Five-point Likert scale } \\
\text { - Never } \\
\text { - Little } \\
\text { - Some } \\
\text { - Much } \\
\text { - Great deal }\end{array}$ & $\begin{array}{l}\text { Five-point Likert scale } \\
\text { - Strongly agree } \\
\text { - Agree } \\
\text { - Uncertain } \\
\text { - Disagree } \\
\text { - Strongly disagree }\end{array}$ \\
\hline Sample size & $n=610$ & $n=133$ & $n=765$ & $n=413$ \\
\hline Institution & $\begin{array}{l}\text { One institution only; (West } \\
\text { Virginia College) }\end{array}$ & $\begin{array}{l}\text { One medical school and } \\
\text { two tertiary care centers } \\
\text { in Taiwan }\end{array}$ & $\begin{array}{l}\text { One institution only; (Penn } \\
\text { State College) }\end{array}$ & $\begin{array}{l}\text { Two institutions in Zagazig } \\
\text { (Egypt) and Dammam } \\
\text { (Saudi Arabia) }\end{array}$ \\
\hline
\end{tabular}

Note: *Number of items of the final version of the instrument.

Sample size recommendation for piloting an instrument should include either a minimum of 10 respondents per item (Nunnaly 1978) or a minimum overall sample of 300 respondents (Comery \& Lee 1992; Henning et al. 2006). Our sample size is, therefore, considered adequate for validation of the instrument in its piloted version.

The Arab world constitutes several countries; one can argue that the inferences of the LAMPS may not be externally valid (generalizable) citing the differences between countries. According to Barakat (1993), although there are differences, 'Arab world' is a single, overarching society rather than a collection of several independent states. We deliberately enrolled medical students and interns from Egypt and Saudi Arabia, where almost one quarter of Arabs live, to expand the spectrum of responses. It was not a surprise that the overall mean scores of the LAMPS among Egyptians and Saudis were 3.9 and 4.0, respectively, which reflects close similarities of attitudes towards medical professionalism.

\section{The LAMPS versus similar instruments}

Since professionalism is closely related to the social contract; i.e. medical professionalism cannot be considered out of the realm of the society. Most of reported studies were conducted on medical students in Western societies; USA $(n=11)$, UK $(n=6)$, and Canada $(n=5)$. None of these instruments may be appropriate for the Arabian context. When reviewing relevant literature, salient features of the "Arabian LAMPS" can be identified. Many of the reported instruments on professionalism do not stem from known domains. The LAMPS, however, was primarily developed based on ABIM (1995) elements of professionalism. The LAMPS is compared with three similar instruments (Nath 2006; Blackall 2007; Tsai 2007), two of them stemming from the same ABIM framework (Table 3).

Items of the LAMPS have been developed jointly by the authors and the panelists. The number of experts who were recruited for content validation of the LAMPS was by far more than others. Also the LAMPS has been administered in two institutions. With critical analysis of items of other instruments, we found that the questionnaire of Nath (2006) consisted of 29 anecdotal statements that are not categorized into domains. The survey of Tsai (2007), however, include extremely short broad terms, e.g. Prudence, Integrity fair or Being straightforward, and long compound ones, e.g. Respect other physicians and professional colleagues such as nurses, medical students, residents, and subspecialty fellows. Items of the LAMPS represent explicit behaviors as micro-scenarios in a comparable word count.

\section{Implications and use of the Arabian LAMPS}

A useful inference is the one that helps us make a decision. The LAMPS not only measures students' attitudes, but also score of the LAMPS' domains and items that can be used to identify the learning gaps in particular areas of professionalism. Identifying the gaps and misconceptions in professionalism among students and helping them rectify these gaps is a key step in fostering professionalism (Hur 2009) and fulfilling social accountability of a medical school (Woollard \& Boelen 2012). Now, the question is: how does the "LAMPS" enable teachers to 
identify these learning gaps and act accordingly? The score of respondents on particular domains on the LAMPS represents their views on professionalism on these domains. If they score low on "respect," for instance, it indicate misunderstanding of the concept of respect. We, as medical teachers, then may consider introducing some educational interventions and using vignettes for reflection to address "respect." Students should also recognize the boundaries of each domain. Every virtue is midway between two non-virtues, e.g. respect to superiors is midway between disrespect and apple polishing. The same is applicable for other domains.

The LAMPS can also be used to track attitude changes on professionalism across different groups and over time. Application of the LAMPS before and after an educational intervention on professionalism helps in evaluating the intervention by the progress in students' learning. Even without intervention, the LAMPS can demonstrate how professionalism is transformed in the minds of medical students throughout medical education by comparing senior and junior students or using the LAMPS in a longitudinal study. This transformation is particularly important in Arabian medical schools for two reasons: (1) professionalism is not, so far, addressed in teaching or assessment, and (2) there is a minimal integration between basic and clinical sciences in traditional curricula.

If the LAMPS is administered to medical students and their teachers, it can estimate the perception gaps in attitudes toward certain aspects of professionalism between the two groups. The perception of teachers can be viewed as a benchmark on professionalism for students, as Hur (2009) reported in the Korean context.

Fine tuning the scale of the LAMPS introduces new implications. The LAMPS can be used to estimate the trend of these behaviors in the community. The leading question can be changed from: "Do you agree when the doctor...?" to be "How often do you encounter a doctor...?" In the "trendy LAMPS," the scale from 1 to 5 represents the frequency of observed behavior ( $1=$ never, $5=$ always $)$. Naturally, common behaviors should be handled with special care depending whether they are positively-worded items (recommended behaviors) or negatively-word items (discouraged behaviors).

When the "trendy LAMPS" is administered to all stakeholders, e.g. students, doctors, nurses, technicians, health administrators, and patients, it will reflect the professional environment within a particular institution, which can be called: "environmental LAMPS." If a negative behavior is found popular, it should be addressed explicitly in faculty development programs to encourage positive role-models among teachers. Szauter (2001) and Quaintance (2008) used students' views to identify problems in faculty' behaviors to customize appropriate faculty development modules in professionalism.

\section{Limitations of the LAMPS}

There is always darkness under the LAMPS. No single instrument can be inclusive of all traits and behaviors of professionalism. We tired our best to sample commonest behaviors within domains of professionalism in a particular context. Medical professionalism is a complex construct that relatively requires more items to address its dimensions. Interestingly, the 28 items of the LAMPS is even less than the average number of similar instruments, which may range from 29 items (Nath 2006) to 36 items (Blackall 2007).

The LAMPS is designed as a context-specific instrument. This is a double-bladed feature which can be considered as a strength and limitation as well. Unlike the Dundee Ready Educational Environment Measure (DREEM), which was developed by Roff and Dherwani (1997) as a culturally nonspecific inventory, the Arabian LAMPS is designed to be a culturally-specific inventory for Arabs. Although the number of responses achieved and the multi-centered approach are quite adequate for a validation study, the LAMPS should be tested more widely to confirm its external validity. We will be looking forward to see our LAMPS shining in other Arabian countries.

\section{Conclusion}

Professionalism must be taught in medical schools, because there is a growing body of evidence that unprofessional behaviors of undergraduates are associated with future disciplinary actions by health authorities. But, teaching professionalism should rely on needs assessment with respect to the context of the learners. To the best of our knowledge, the LAMPS is the first validated and reliable tool to measure attitudes toward professionalism in the Arabian context.

\section{Acknowledgements}

The authors wish to thank the 32 panelists, who contributed to content validation and item development of the LAMPS. Sincere appreciation to Prof. Khalid Al-Umran, Dr Mona Al-Sheikh, Dr Rasha Al-Sheikh, Dr Mohammed Al-Hariri, Dr Mohammad Al-Qahtani, Dr Khaled Kamaleddin (University of Dammam, Saudi Arabia) and Prof. Abdul-Latif Zayed (University of Zagazig, Egypt) for their efforts to facilitate pilot testing of the LAMPS. Special thanks to Ms Smitha Royes and Mr Muhammad Zeeshan for statistical analysis of the LAMPS.

The publication of this supplement has been made possible with the generous financial support of the Dr Hamza Alkholi Chair for Developing Medical Education in KSA.

Declaration of interest: The authors report no conflicts of interest. The authors alone are responsible for the content and writing of the article.

\section{Notes on contributors}

MOHAMED M. AL-ERAKY, MBBCh, MSc, MMedEd, is a lecturer of medical education at the University of Dammam, Saudi Arabia. He was also a founding member of Medical Education Development Center at Zagazig University, Egypt and is currently a PhD fellow at the University of Maastricht.

MADAWA CHANDRATILAKE, MMBS, MMedEd, is a research officer and a $\mathrm{PhD}$ graduate in the Centre for Medical Education at the University of Dundee, UK, and his research interests include professionalism and assessment. 
GOHAR WAJID, PhD, Assistant Professor of Medical Education, University of Dammam, Saudi Arabia. He is consultant to the Master in Health Professions Education Programs at Khyber Medical University and the University of Lahore, Pakistan.

JEROEN DONKERS, PhD, is an assistant professor at the Department of Educational Development and Research, Faculty of Health, Medicine, and Life Sciences, Maastricht University, the Netherlands.

JEROEN J.G. VAN MERRIËNBOER, PhD, is a Full Professor of Learning and Instruction at the Department of Educational Development and Research, Faculty of Health, Medicine and Life Sciences, Maastricht University. He is a Research Programme Director of the School of Health Professions Education and Scientific Director of the Interuniversity Center for Educational Research.

\section{References}

ABIM. 1995. Project professionalism by the ABIM (American Board of Internal Medicine). [Accessed 17 January 2012] Available from http:// www.abimfoundation.org.

ACGME. 2011. Outcome project. [Accessed 4 January 2011] Available from http://www.acgme.org.

Adkoli BV, Al-Umran KU, Al-Sheikh M, Deepak KK, Al-Rubaish AM. 2011 Medical students' perception of professionalism: A qualitative study from Saudi Arabia. Med Teach 33(10):840-845.

Al-Eraky MM, Chandratilake M. 2012. How medical professionalism is conceptualised in Arabian context: A validation study. Med Teach 34(Suppl 1):S90-S95, PubMed PMID: 22409198.

Aramesh K, Mohebbi M, Jessri M, Sanagou M. 2009. Measuring professionalism in residency training programs in Iran. Med Teach 31(8):e356-e361.

Barakat H. 1993. The Arab world: Society, culture and state. Berkeley: University of California Press.

Blackall GF, Melnick SA, Shoop GH, George J, Lerner SM, Wilson P K, Pees RC, Kreher M. 2007. Professionalism in medical education: The development and validation of a survey instrument to assess attitudes toward professionalism. Med Teach 29:e58-e62.

Blakey H, Blanshard E, Cole H, Leslie F, Sen R. 2008. Are medical students socially exclusive? A comparison with economics students. Med Educ 42(11):1088-1091, [Epub 2008 Sep 20].

Blue AV, Crandall S, Nowacek G, Luecht R, Chauvin S, Swick H. 2009. Assessment of matriculating medical students' knowledge and attitudes towards professionalism. Med Teach 31(10):928-932.

Chandratilake M, McAleer S, Gibson J. 2012. Cultural similarities and differences in medical professionalism: A multi-region study. Med Educ 46(3):257-266, PubMed PMID: 22324525.

Chandratilake M, McAleer S, Gibson J, Roff S. 2010. Medical professionalism: What does the public think? Clin Med 10(4):364-369.

Chard D, Elsharkawy A, Newbery N. 2006. Medical professionalism: The trainees' views. Clin Med 6(1):68-71.

Clark LA, Watson D. 1995. Constructing validity: Basic issues in objective scale development. Psychol Assess 7:309-319.

Comery AL, Lee HB. 1992. A first course in factor analysis. Hillsdale, NJ: Erlbaum.

Cruess SR. 2006. Professionalism and medicine's social contract with society. Clin Orthop Relat Res 449:170-176.

Cruess SR, Cruess RL, Steinert Y. 2010. Linking the teaching of professionalism to the social contract: A call for cultural humility. Med Teach 32(5):357-359.

Davis RL, Wiggins MN, Mercado CC, O'Sullivan PS. 2007. Defining the core competency of professionalism based on the patient's perception. Clin Experiment Ophthalmol 35(1):51-54.
Ephgrave K, Stansfield RB, Woodhead J, Sharp WJ, George T, Lawrence J. 2006. The resident view of professionalism behavior frequency in outstanding and "not outstanding" faculty. Am J Surg 191(5):701-705.

Finn G, Garner J, Sawdon M. 2010. 'You're judged all the time!' Students' views on professionalism: A multicentre study. Med Educ 44(8):814-825.

Gable RK, Wolf MB. 1993. Instrument development in the affective domain. 2nd ed. Boston: Kluwer Academic Publishers.

Green M, Zick A, Makoul G. 2009. Defining professionalism from the perspective of patients, physicians, and nurses. Acad Med 84(5):566-573.

Henning JM, Weidner TG, James J. 2006. Peer-assisted learning in the athletic training clinical setting. J Athl Train 41(1):102-108.

Hur Y. 2009. Are there gaps between medical students and professors in the perception of students' professionalism level? - Secondary publication. Yonsei Med J 50(6):751-756.

Jha V, Bekker HL, Duffy SR, Roberts TE. 2006. Perceptions of professionalism in medicine: A qualitative study. Med Educ 40(10):1027-1036.

Nath C, Schmidt R, Gunel E. 2006. Perceptions of professionalism vary most with educational rank and age. J Dent Educ 70(8):825-834.

Nunnaly J. 1978. Psychometric theory. New York, NY: McGraw-Hill.

Pett MA, Lackey NR, Sullivan JJ. 2003. Making sense of factor analysis: The use of factor analysis for instrument development in health care research. Thousand Oaks, CA: Sage.

Quaintance JL, Arnold L, Thompson GS. 2008. Development of an instrument to measure the climate of professionalism in a clinical teaching environment. Acad Med 83(10 Suppl):S5-S8.

Ratanawongsa N, Bolen S, Howell EE, Kern DE, Sisson SD, Larriviere D. 2006. Residents' perceptions of professionalism in training and practice: Barriers, promoters, and duty hour requirements. J Gen Intern Med 21(7): $758-763$.

Roberts LW, Green Hammond KA, Geppert CM, Warner TD. 2004. The positive role of professionalism and ethics training in medical education: A comparison of medical student and resident perspectives. Acad Psychiatry 28(3):170-182.

Robins LS, Braddock 3rd CH, Fryer-Edwards KA. 2002. Using the American Board of Internal Medicine's "Elements of Professionalism" for undergraduate ethics education. Acad Med 77(6):523-531.

Roff S, Dherwani K. 1997. Recommended responses to lapses in professionalism. Clin Teach 8(3):172-175.

Sadat-Ali M. 2004. Professionalism: Are we doing enough? Saudi Med J 25(5):676-677.

Sehiralti M, Akpinar A, Ersoy N. 2010. Attributes of a good physician: What are the opinions of first-year medical students? J Med Ethics 36(2):121-125.

Suzuki N. 2009. Certification for specialists on neurology by Japanese Society of Neurology. Rinsho Shinkeigaku 49(11):745-746.

Szauter K, Turner HE. 2001. Using students' perceptions of internal medicine teachers' professionalism. Acad Med 76(5):575-576.

Tsai TC, Lin CH, Harasym PH, Violato C. 2007. Students' perception on medical professionalism: The psychometric perspective. Med Teach 29(2-3):128-134.

Wiggins MN, Coker K, Hicks EK. 2009. Patient perceptions of professionalism: Implications for residency education. Med Educ 43(1):28-33.

Woollard B, Boelen C. 2012. Seeking impact of medical schools on health: Meeting the challenges of social accountability. Med Educ 46(1):21-27.

Zaini R, Ben Abdulrahman K, Al-Khotani A, Al-Hayani A, Al-Alwan I, Jasaniah S. 2011. Saudi Meds: A competence specification for Saudi medical graduates. Med Teach 33:582-584. 